\title{
ANALISANDO A FERRAMENTA AVALIAÇ̃O DE APRENDIZAGEM EM PROCESSO DA SECRETARIA DA EDUCAÇÃO BÁSICA DO ESTADO DE SÃO PAULO COMO MÉTODO DE ENSINO DE LÍNGUA MATERNA
}

\section{ANALYSING THE LEARNING EVALUATION AS A PROCESS TOOL OF THE SÃO PAULO STATE SECRETARIATS OF EDUCATION AS A METHOD FOR THE MOTHER TONGUE LEARNING}

\section{Michelle de Souza Prado ${ }^{1}$ Daniela Nogueira de Moraes Garcia ${ }^{2}$}

Resumo: A Avaliação da Aprendizagem em Processo (AAP) é um coeficiente adotado pela Secretaria da Educação do Estado de São Paulo (SEESP), desde 2011, como forma de analisar o aprendizado de estudantes do ciclo fundamental II e médio com relação à aprendizagem de Língua Portuguesa (LP). Basearemos nossas discussões em SOLÉ (1998), MARCUSCHI (2010), DIONÍSIO; VASCONCELOS (2013) e de outros textos científicos produzidos por PRADO; GARCIA (2017). Trata-se de aumentar a visibilidade e transparência a um método avaliativo de língua materna, o qual já atingiu um status de institucionalizado dentro do maior Estado do país e carece de observações.

Palavra-chave: avaliação de aprendizagem em processo; Secretaria da Educação do Estado de São Paulo; língua portuguesa.

Abstract: The Learning Evaluation as a Process (LEP) is a measurement pattern that has been applied by the São Paulo State Secretariats of Education since 2011 as a way of analyzing the students' levels of Portuguese Language (PL) learning in the middle and high school levels of education. Our discussions are based on SOLÉ (1998), MARCUSCHI (2010), DIONÍSIO; VASCONCELOS (2013) and other papers produced by PRADO; GARCIA (2017). Our purpose is to raise visibility and transparency for a mother tongue evaluative method that has already reached an institutionalized status in the largest State of the country and lack a careful look on it.

Keywords: learning evaluation as a process; São Paulo State Secretariats of Education; Portuguese language.

\section{Introdução}

\footnotetext{
${ }^{1}$ Mestre em Letras pelo ProfLetras da Universidade Estadual Paulista Júlio de Mesquita Filho (UNESP). E-mail: michelle_prado@hotmail.com

${ }^{2}$ Doutora em Estudos Linguísticos pela Universidade Estadual Paulista Júlio de Mesquita Filho, IBILCE. É Professora Assistente da FCL, UNESP, Campus de Assis. Realizou sua pesquisa de pós-doutorado pelo Spanish and Portuguese Department da Georgetown University (Washington, DC- United States of America) em 2015. Atua no programa de pós-graduação PROFLETRAS -UNESP e na consultoria dos alunos-professores do Centro de Línguas e Desenvolvimento de Professores e da UNATI. Foi coordenadora do PIBID- Inglês e, no momento, atua como coordenadora do Nucli IsF do Inglês sem Fronteiras na FCL- UNESP- Assis. É professora mediadora nas sessões de interação e mediação no teletandem e integra o Grupo de Pesquisa: Teletandem: Transculturalidade das interações online via webcam. E-mail: dany7garcia@gmail.com
} 
O presente trabalho é fruto de observação interior do funcionamento, aplicação e avaliação dos resultados e impactos em uma sala de $8^{\circ}$ ano, da Avaliação de Aprendizagem em Processo (AAP) ao longo de um ano letivo no bojo de uma escola estadual do interior paulista. Num primeiro momento, faz-se mister explicar em síntese o que é este novo instrumento de avaliação que foi incluída pela Secretaria da Educação do Estado de São Paulo (SEESP) e se padronizou na rede.

A Avaliação de Aprendizagem em Processo, implementada no sistema público por medida do governo estatal tem por função precípua, destacada pela diretriz que norteia sua criação, continuidade e aplicação, avaliar e acompanhar o desenvolvimento do currículo em duas disciplinas consideradas carros-chefes no currículo de São Paulo: Português e Matemática e, por serem estas disciplinas, alvos de quantificadores educacionais de escala mundial como o Programa Internacional de Avaliação de Estudantes (PISA). Ambas as avaliações com perfil quanti-qualitativo, em outras palavras, mensurado o grau de respostas certas e não certas através de questionário conteudístico estruturado pela Secretaria, fundamentado no conteúdo programático para aquela dada série em questão, o qual, por sua vez, baseia-se nos Parâmetros Curriculares Nacionais (BRASIL, 1997) e na Proposta Curricular do Estado de São Paulo (SÃO PAULO, 2008). Nossa busca desde o mestrado profissional é a contribuição aos estudantes no aprendizado de língua materna.

O formato da AAP mudou muito ao longo dos anos. De início, como todo projeto ainda piloto, nem todas os anos escolares eram avaliados. O caderno de questões já teve várias configurações: com dez, doze, quinze ou vinte e quatro questões objetivas; com alguma questão aberta; com apresentação de produção textual mediante um gênero pré-estipulado com texto motivador; aplicação anual, semestral e, posteriormente, bimestral. Também as formas de tabulação sofreram mudanças abruptas. De início, a implantação da AAP foi turbulenta e ainda trazia muitas arestas e novidades com as quais a equipe educacional não estavam aptas a lidar. Em outras palavras, foram períodos instáveis em que não se sabia quais seriam os rumos e as características da AAP. Muitos dados foram perdidos por falta de compilação adequada ou, nem mesmo, utilizados para o fim a qual se destinava: o acompanhamento do aprendizado dos estudantes.

Em 2015, podemos dizer, com um quinquênio de existência, foi o marco de que a Avaliação veio para ficar, pois atingiu um status estável, definiu um perfil mais sólido: questões 
apenas objetivas, retirada da produção textual, e todo o gabarito do aluno era lançado, dentro de um sítio eletrônico, o Sistema de Acompanhamento do Resultado de Avaliações- SARA, alojado em espaço da Secretaria Digital, criado pela SEESP para inserir a vida acadêmica dos matriculados.

Por mais que não eram avanços circunstanciais no fator pedagógico, porque ainda muito depende do preparo docente para saber trabalhar os dados obtidos, houve uma inserção de um novo olhar, uma reeducação dos professores de língua materna para a compreensão de que tudo ali produzido diz algo sobre a recepção do conteúdo em sala: não só acertos apontam avanços, como também os distratores, dito de outra forma, aquelas questões não consideradas corretas, mas que foram alvo de escolha dos educandos. Deste modo, uma única questão abre veredas de possibilidades a serem observadas.

E, justamente, é esta faceta, a compreensão dos caminhos da sala durante o desenvolvimento da questão sobre conteúdos de Língua Portuguesa prescritos por documentos oficiais na matriz de competências e habilidades, que este estudo vem apresentar, em forma de recorte de um estudo de caso.

\section{Um novo sistema de avaliação em língua materna para rede básica paulista:}

O cunho avaliativo da Avaliação de Aprendizagem em Processo é de caráter diagnóstico-formativo, porque tem a pretensão de diagnosticar pontos frágeis sobre o que os alunos deveriam aprender para aquele dado ano em que está cursando, competências e habilidades descritas em uma matriz presente na Proposta Curricular do Estado de São Paulo (2008). Formativa porque são através destas constatações que o plano de ação deve ser baseado até que o ponto nevrálgico seja sanado. Em teoria subsidia as ações, o planejar e replanejar da recuperação contínua e integrada da série em que se está matriculado:

\footnotetext{
Essa ação, fundamentada no Currículo do Estado de São Paulo, tem como objetivo fornecer indicadores qualitativos no processo de aprendizagem do educando, a partir de habilidades prescritas no Currículo. Dialoga com as habilidades contidas no SARESP, SAEB, ENEM e tem se mostrado bem avaliada pelos educadores da rede estadual. Propõe o acompanhamento da aprendizagem das turmas e do aluno de forma individualizada, por meio de um instrumento de caráter diagnóstico. Objetiva apoiar e subsidiar os professores de Língua Portuguesa e de Matemática que atuam nos Anos Finais do Ensino Fundamental e no Ensino Médio da rede Estadual de São Paulo, na elaboração de estratégias para reverter desempenhos insatisfatórios, inclusive em processos de recuperação. (SÃO PAULO, 2015, p.2 A)
}

Portanto, o professor pode lecionar em classes de mesma série mas, nem por isto, seu plano de aula pode ser o mesmo, porque depende do diagnóstico de cada uma. Sua proposta 
está em fazer um trabalho mais refinado que outras avaliações em larga escala e das quais a AAP é afiliada, sendo aquelas não possíveis de ofertar um espelho de desempenho no decorrer do ano, porque, em geral, aplicam-se ao final do mesmo, os resultados obtidos são por blocos de mesma seriação, de modo algum, prevê as idiossincrasias referentes a classe A, B, C e assim por diante.

Em se tratando de uma avaliação sobre o aprendizado em LP, vale mencionar, como ficará explícito no próximo tópico que perspectiva de língua que é manifestada, ou seja, a qual interessa à Secretaria avaliar e monitorar a aprendizagem é a língua normativa, o que, de certa forma, delimita o contexto mosaico que temos em sala de aula de escolas públicas:

[...] a escolha de uma gramática para ser manuseada na escola deve considerar, pelo menos, dois fatos importantes: (i) todo falante natural de uma língua é competente, isto é, não há que se valorizar a máxima pulverizada entre uma parcela das pessoas, que insiste em dizer que não sabe "português". Todo falante é capaz de ativar esquemas cognitivos, produzir enunciados, independente de ter conhecimento prévio das regras da gramática; e (ii) o estudo da língua materna representa a explicação reflexiva que se faz dessa língua por meio de seu funcionamento, uma vez que a língua é viva e, por isso, escapa aos moldes pré-definidos. Deve-se eleger, assim, uma gramática que esteja de acordo com o uso e que, portanto, parta dela para fundamentar a regra. (LOPES-DAMASIO, PRADO, et al., 2018)

Outra faceta que gostaríamos de esclarecer neste trabalho sobre a aplicação, desenvolvimento e recolha de resultados através da AAP é que a ferramenta é utilizada por gestores e pelo próprio governo para monitorar o trabalho do professor de língua portuguesa regente da sala. Isso porque, ao entender destas outras instâncias que se encontram para além do trabalho docente in loco, mesmo se tratando de um teste padronizado que não leva em consideração nuances como o tempo e a vontade de aprender do próprio aluno, os resultados considerados não positivos dizem respeito à qualidade do profissional e desconsidera o que o teste não consegue medir. É uma forma de controle do fazer docente que, se por um lado, propõe uma marcha curricular para os formadores em LP de forma que todos tenham acesso equilibrado ao capital cultural ofertado, em todo território paulista, visto que somos a maior federação brasileira e o acompanhamento do cotidiano da rede é tarefa hercúlea, por outro, minimiza a condição multicultural por excelência do ensino gratuito, dando um tom um tanto quanto fordista às aulas de língua materna. Em outras palavras, a padronização das linhas de montagem em resposta ao tipo ideal colocado pela empresa por índices, cujas formulações advém de secretaria ou diretorias de ensino, programas nacionais e internacionais que aferem a qualidade da educação nos países. 
Enfim, a AAP caminha para sua primeira década de existência e angariou perenidade como coeficiente avaliativo na rede pública paulista. Possui características demarcadas, mas como estamos a refletir ao longo de distintos trabalhos, em especial durante o nosso mestrado profissional, PROFLETRAS, há a necessidade de correções das reais metas dos resultados levantados a cada edição aplicada, já que a mesma tem como função precípua auxílio na prática pedagógica no ensino-aprendizagem de LP e mobiliza recursos pessoais e financeiros das unidades escolares ao longo de todo ano letivo. Diante do que argumentamos até aqui, apresentamos, abaixo, um semestre de aplicação da Avaliação, para que seja observada em funcionamento.

\section{A AAP na prática: apresentação de um estudo de caso}

Segundo a coleta de dados realizada, sob uma ótica qualitativa, a AAP do $1^{\circ}$ semestre de $2015,8^{a}$ edição, apresentou 10 questões objetivas e contou com a colaboração de 32 alunos do $8^{\circ}$ ano do Ensino Fundamental de uma escola pública do interior do Estado de São Paulo, a qual era a docente de língua portuguesa responsável. O Gráfico 1, plotado e compartilhado, abaixo, ilustra melhor como foram as ocorrências de acertos e equívocos:

Gráfico 1 - Resultado da AAP na $8^{\text {a }}$ edição, $1^{\circ}$ semestre de 2015

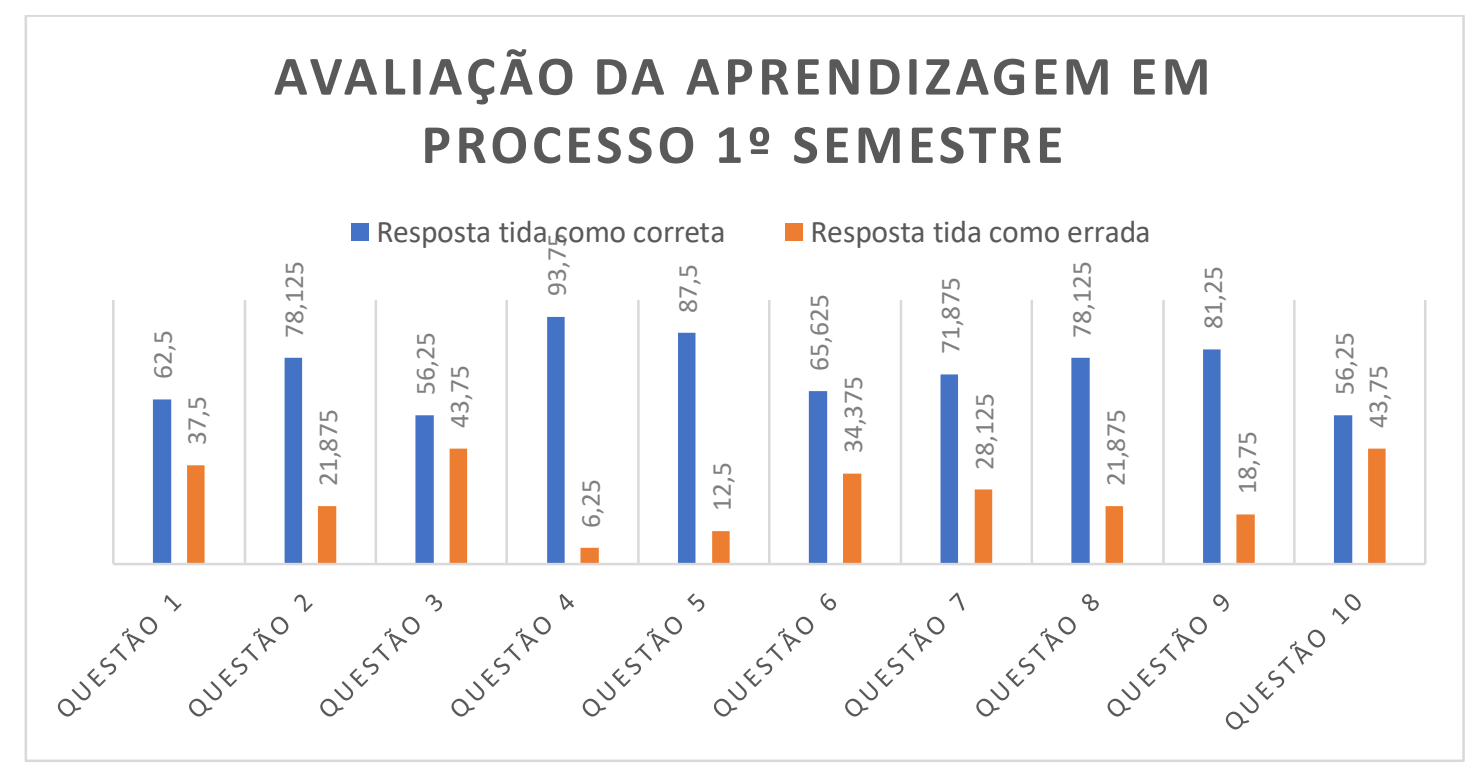

Fonte: Autores

Nota-se, claramente, que, em todas as questões, os alunos tiveram maiores índices de acertos. Como foi salientado, anteriormente, a proposta pedagógica da AAP é diagnosticar 
avanços e dificuldades da sala frente ao conteúdo de LP que devem ter domínio no ano em que estão matriculados. Diante das divergências apresentadas entre Habilidades $(\mathrm{H})$ versus Competência (C), o docente desenvolve seu Plano de Ação (PA) levando em conta o conteúdo a ser atingido. No próximo capítulo, após a análise de dados, elencaremos as propostas metodológicas que adotamos para o PA do oitavo ano. Portanto, destacamos, nesta primeira aplicação, as questões de número 3 e 10, as quais apresentam a maior taxa de não acertos. Segundo a Matriz de Competência e Habilidade do Caderno Pedagógico que norteia o trabalho do professor com as referidas edições, questão 3, busca "estabelecer relações de causa e consequência, entre partes e elementos de um texto" e a questão 10, "identificar a sequência lógica dos fatos em um texto". (AAP, 8 a edição, 2015, p. 4 A)

Vejamos o terceiro enunciado, disposto na Figura 1 que se segue, da AAP e sua divisão entre gabarito e distratores:

Figura 1 - Texto e enunciado da questão 3. 
Leia o texto e responda à questão 3.

\section{Qualidade do ar afeta a saúde dos animais domésticos}

Por Isabela Mena

Com a chegada do outono, a cachorrada comemora. Brisa e temperaturas mais amenas tornam qualquer passeio mais agradável até mesmo para os donos. Mas o clima atípico das últimas semanas, calor intenso e baixa umidade do ar, tem dificultado a dispersão dos poluentes na atmosfera e muitos bichinhos tiveram de trocar o passeio no parque pelo programa de que menos gostam: visitar o veterinário.

No Hospital Veterinário Sena Madureira o número de casos de animais domésticos com queixas relacionadas à poluição aumentou $30 \%$ nesse período. De acordo com o veterinário Mário Marcondes, cardiologista do hospital, os sinais mais comuns são olhos vermelhos e lacrimejantes, mucosa ressecada, coriza e tosse, tanto em gatos como em cachorros. "Nos animais que já têm algum tipo de doença respiratória crônica, como bronquite ou asma, os sintomas são mais severos, como falta de ar." [...]

Disponivel em: <http://www1.folha.uol.com.br/folha/equilibrio/noticias/ult263u4421.shtml>. Acesso em: 31 de julho de 2014. (adaptado)

\section{Questão 3}

O calor intenso e a baixa umidade do ar aumentam o índice de poluição na atmosfera, causando

(A) olhos vermelhos e lacrimejantes.

(B) a dispersão de poluentes na atmosfera

(C) temperaturas amenas e agradáveis.

(D) diminuição de doenças respiratórias.

Fonte: (AAP, $8^{\text {a }}$ edição, 2015, p. 13A)

Diante do enunciado e das escolhas dos adolescentes entre as quatro alternativas, obtemos o

\section{Gráfico 2:}

Gráfico 2 - Porcentagem da escolha dos estudantes entre alternativa correta e distratores na questão 3. 


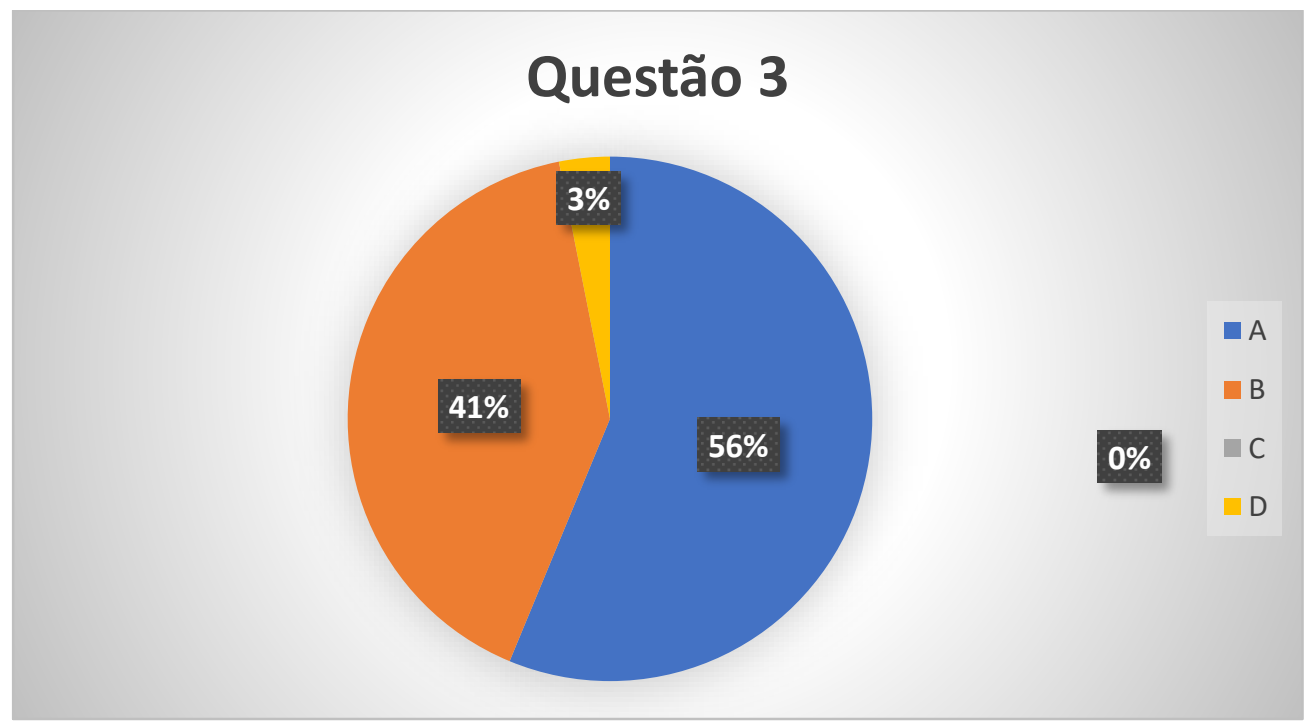

Fonte: Autores

$\mathrm{Na}$ terceira questão, a alternativa correta é a letra A. No entanto, boa parte dos alunos se dividiu, de forma equilibrada, entre as alternativas A e B. Vale mencionar que ninguém optou pela $\mathrm{C}$ e apenas um estudante ficou com a opção D.

É um texto da esfera jornalística. Podemos fazer este reconhecimento devido ao formato típico: manchete, impessoalidade, objetividade e a fonte completa nossa dedução. Não que o reconhecimento do gênero tenha algum impacto sobre o horizonte de resposta esperado pela questão. Tanto assim que, em nenhum momento, o Caderno de Questões faz menção a isto. Ao contrário, retira a roupagem que o referido trecho tem que o faz circular socialmente como uma notícia e o chama, genericamente, de texto

Agora, o mesmo para a décima questão (Figura 2):

Figura 2 - Texto e enunciado da questão 10 
Leia o texto e responda à questão 10.

\section{O macaco e o leopardo}

Júlio Emílio Braz

Numa certa manhã, o Leopardo, atormentado por dias e dias sem comer um só pedaço de carne, saiu para caçar. Esfomeado, esgueirou-se sorrateiramente floresta adentro, os passos ainda mais silenciosos, os olhos extremamente atentos ao menor dos movimentos, a necessidade crescendo à mesma medida que o estômago vazio roncava cada vez mais de modo incômodo e persistente. Caminhava de tal maneira angustiado, faminto, que mal se deu conta de um grande buraco que, de repente, surgiu em seu caminho.

É claro que não se tratava de um buraco qualquer, aberto pelo tempo e pelo acaso, mas um buraco cuidadosamente feito e tapado com uma abertura astuciosa de galhos e folhas secas, ou seja, tratava-se de uma armadilha.

Surpreso e assustado, esqueceu-se por uns instantes da tremenda fome que sentia e procurou escapar. Não conseguiu. Andando de um lado para o outro, inconformado e, por fim irritado, rugia para todos os lados, dando violentas patadas dentro daquele terrível buraco que o aprisionara. [...]

BRAZ, Júlio Emílio (adapt.). Lendas da Africa. Rio de Janeiro: Bertrand Brasil, 2005. p. 10.

\section{Questão 10}

Imediatamente antes de cair na armadilha, o Leopardo

(A) "caminhava de tal maneira angustiado, faminto, que mal se deu conta de um grande buraco que, de repente, surgiu em seu caminho."

(B) "estava andando de um lado para o outro, inconformado e, por fim irritado, rugia para todos os lados."

(C) "atormentado por dias e dias sem comer um só pedaço de carne, saiu para caçar."

(D) "esqueceu-se por uns instantes da tremenda fome que sentia e procurou escapar."

Fonte: (AAP, 8 a edição, 2015, p. 26 A)

Nos dados de respostas gerados para a questão 10, o que mais contrasta é o fato de que, somados às porcentagens dos distratores $\mathrm{B}, \mathrm{C}$ e D, a porcentagem total de escolhas incorretas, $63 \%$, é esmagadora sobre o percentual de $37 \%$ que escolheram a alternativa do gabarito oficial, letra A. Observe o Gráfico 3: 
Gráfico 3: Porcentagem da escolha dos estudantes entre alternativa correta e distratores na questão 10.

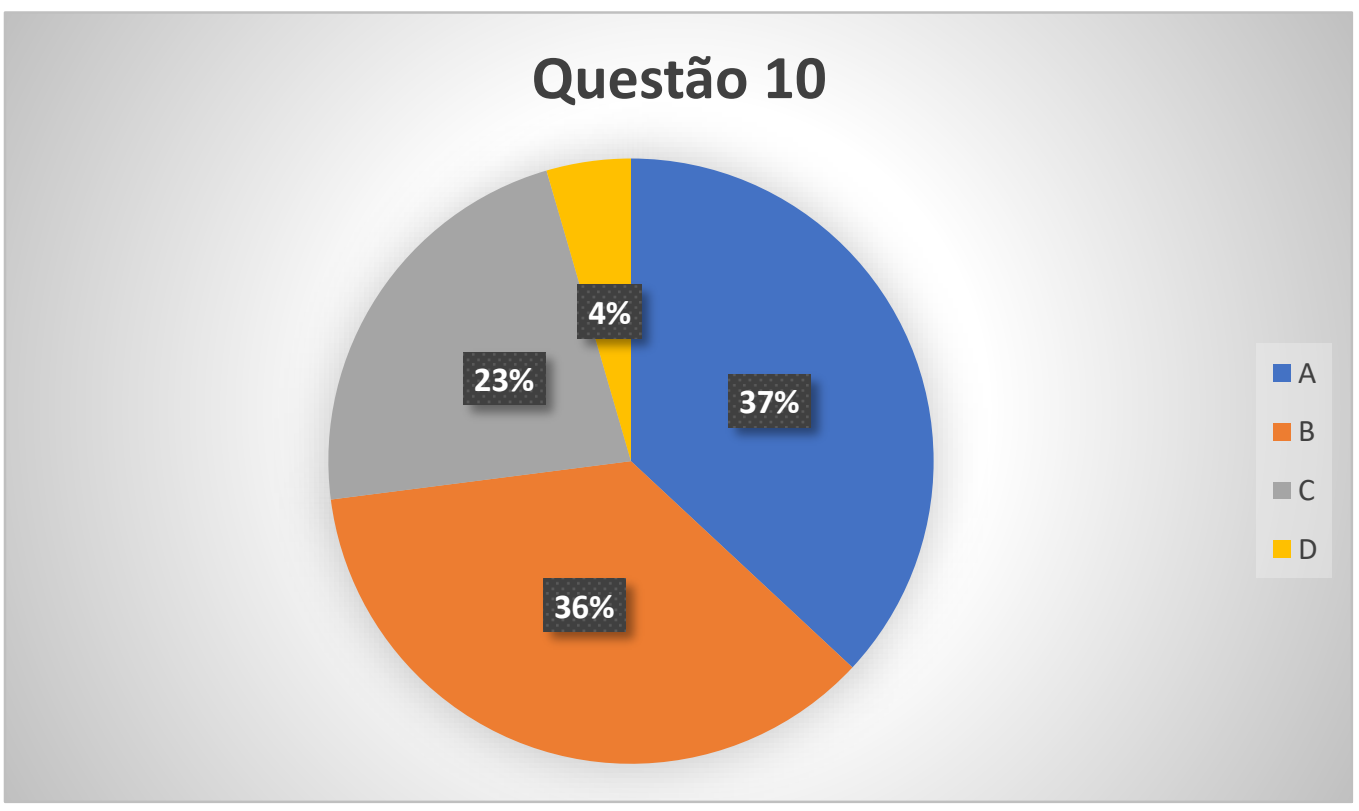

Fonte: Autores

$\mathrm{Na}$ última questão, também, há um equilíbrio entre a resposta considerada certa, alternativa A (37\%) e a alternativa não aceita como certa B (36\%). Aqui, ao contrário da questão anterior, houve uma divisão maior entre as alternativas $\mathrm{C}$ e $\mathrm{D}$, também, não consideradas corretas. Ainda assim, a preferência ficou com a letra B.

Tal qual o outro, não há menção do gênero. Também está destituído de seu nome e, reconhecer que se trata de uma lenda (atemporal, sem dados fidedignos de localização e sem compromisso com a realidade, apresenta um aspecto moralizante), é mais importante para um ato próprio de conhecimento prévio do que uma implicação necessária para desarmar a questão.

Esta falta de interesse pela origem do texto, talvez, seja por um dos dois fatores: ou se espera que o educando tenha introjetado os domínios discursivos presentes na AAP do oitavo ano ou que eles acertem a questão baseados na interpretação textual, independente de reconhecerem com qual atividade linguística estão lidando. "Já se tornou trivial a ideia de que os gêneros textuais são fenômenos históricos, profundamente vinculados à vida cultural e social" (MARCUSCHI, 2010, p. 19). De fato, ainda que trivial, não deveriam ser assim nivelados por baixo, ou seja, seu formato e contexto de existência, preteridos na resolução dos enunciados. Estes recortes anárquicos e o tratamento homogêneo destes excertos apenas com textos, à revelia de sua natureza, indiferente das características que cada gênero textual possa oferecer, não permite que o aluno possa acionar seu conhecimento sobre o formato do gênero 
e utilizá-lo para resolução da questão. Concordamos com a seguinte colocação de Santos (2007), “Ao não entrarmos nas especificidades que compõem as mediações histórico-sociais presentes nas diferentes formas de se conceber o fenômeno educativo, corremos o risco de sermos simplistas” (p.13). A observação in loco da realização da Avaliação fez notar que a desterritorialização dos gêneros, para colocá-los em base comum, realizando um recorte descontextualizado, apenas com uma finalidade didatizadora de "avaliar", desmotiva todas as aprendizagens que o aluno poderia mobilizar para destravar a questão, além de banalizar a potencialidade do gênero textual, sua função social e histórica. A afirmação de Dionísio e Vasconcelos (2013) sobre a exigência de um "repensar metodológico que permita termos consciência do estamos provocando, dos efeitos de utilização de métodos e estratégias nos aparatos neuropsicológicos do aluno" (p. 24), clarifica o observado. Em outras palavras, o pensamento de erigir uma habilidade sacrificando todas as demais que poderiam ser trabalhadas pela AAP é reducionista nos enunciados e castrante no tocante ao que se é a avaliação da aprendizagem em língua materna.

Interessante foi notar, e na realidade foi um dos pressupostos que tomamos por base para desenvolver as atividades do Plano de Ação, que ambas as questões têm uma vertente próxima, porque dependem de que o leitor seja capaz de estabelecer causa e consequência entre as partes textuais, ou seja, observar o fragmento pinçado para compor a unidade discursiva como etapa de um todo articulado. Na primeira, entendida como questão 3, é necessário compreender que a consequência do tempo seco para os animais são os olhos vermelhos e lacrimejantes e, já na última, compreendida como sendo a décima, tem que se prestar atenção no que antecede a consequência de cair na armadilha: caminhar, desordenadamente, e preocupado com a própria fome.

Mas já se faz jus indagar o porquê de tantos alunos se oporem ao resultado da matriz de conhecimentos e indicarem outros horizontes. Tomamos, para início, a resposta $\mathrm{B}$ da questão terceira que acolheu $41 \%$ de escolha dos adolescentes, embora seja "errônea". O distrator, alternativa incorreta que, também, apresenta alto nível de plausibilidade com a questão "(B) a dispersão de poluentes na atmosfera", poderia ser a resposta correta, também, porque, para responder, os alunos acionaram os conhecimentos intertextuais os quais possuem o qual diz que o aumento do índice de poluição aérea é também pela dispersão de partículas nocivas nos ares. Logo, a escolha não foi anárquica e os 13 estudantes que apontaram esta resolução partiram das inferências de sentido aliadas ao próprio texto que diz que a baixa umidade do ar "tem 
dificultado a dispersão dos poluentes na atmosfera". Como não existe objeto que não seja cercado de outro discurso, todo discurso dialoga com outros discursos, toda palavra é cercada de outra palavra (Bakhtin,1992, p.319, apud Fiorin, 2010). Por fim, a questão descarta o que o próprio texto traz em seu bojo e o conhecimento do assunto que os adolescentes possuem e utilizam quando se deparam com a temática.

No caso da questão 10, foram 8 alunos que escolheram o distrator B e 5 o distrator C. Todas as opções apresentam elementos intratextuais, com pequenas nuances. As letras B e D são a descrição de um momento ulterior, queda na armadilha, ao demandado pela questão que perguntam sobre o que ocorreu anteriormente à ação do Leopardo ser aprisionado. A força do questionamento está no advérbio temporal "antes", o que levaria tanto à questão A, alvo da maior margem de escolha (37\%), como até a C. Mas o texto (como é chamado na própria Avaliação) pede um grau de especificidade mais refinado, sacrificando outros atos de locução. A alta porcentagem de opção pela alternativa $\mathrm{B}$, se deu por causa da forma como a alternativa está recortada “(B) estava andando de um lado para o outro, inconformado e, por fim irritado, rugia para todos os lados". Paira, neste intervalo, um sentido completo e que pode servir para qualquer momento dos acontecimentos do felino faminto que sai à caça, porém a referência do excerto não está nela mesma, necessita do retorno à lenda para completar a frase ("dentro daquele terrível buraco") e ver que ela não corresponde ao antes. O lapso dos alunos ocorre por se fiarem apenas na alternativa e não retornarem à fonte. $\mathrm{O}$ efeito perlocucionário de persuasão da resposta incorreta foi aceito pelos avaliados que não fizeram como a maioria de retomar a autoridade textual.

Podemos afirmar que, no caso desta questão, o diagnóstico dos alunos que não desenvolveram a habilidade de identificar a sequência lógica está mais claro e delimitado, porque há a preocupação de especificar o tempo. Se bem que concordamos com Solé (1998, p.26) quando diz: “A meu ver, não se trata de um erro de decodificação, mas de um fato muito frequente nos bons leitores: a partir dos conhecimentos que temos e da informação que o texto nos dá, aventuramos - prevemos - o que vem a seguir", distinto do enunciado retirado da notícia de jornal, ambígua e passível de ser anulada pelos defeitos apontados.

$\mathrm{O}$ que nos fica de experiências como a que aqui dividimos, tanto diante dos dados qualitativos arrolados, quanto mediante as trocas que foram possíveis ter com a sala do $8^{\circ}$ ano, conhecendo o percurso de aprendizagem da mesma, é que pouco importa para resolver estas questões que apresentaram maior índice de erro mobilizar conhecimentos prévios. Qualquer 
aluno poderia realizar o trabalho de interpretar as questões e tal fator não está ligado à questão da matriz de competências e habilidades dos documentos oficiais dispostas para esta série. A visão da AAP sobre língua materna e avaliar o nível coeficiente do aluno leitor é empobrecedora quando feita de modo apenas a captar se o aluno leu ou não, naquele exato momento de aplicação da Avaliação, o "texto” com atenção.

Em que pese outro fator de impacto na AAP, talvez pelo interesse demasiado por avaliar o estilo formal da língua materna e preterir outras dimensões conforme debatido, é a falácia que formulação de algumas questões faz o aluno incorrer:

\begin{abstract}
Dito de outra forma, com a intenção de afinar com este estudo de caso, o que fica entendido nas edições da $A A P$, sobretudo, com este exemplo demonstrado, é o descarte de dimensões importantes dos enunciados, como a presença do pictórico e, porque usou as inferências e previsões imediatas dos alunos para induzi-los ao erro, ao invés de utilizar caminhos para chegar ao acerto. (GARCIA, PRADO, 2017, p. 684)
\end{abstract}

São mecanismos de armadilha linguística que solapam a própria missão da AAP de ser uma Avaliação de caráter diagnóstico que pretende fornecer pistas ao docente de LP responsável para que este elabore ações pedagógicas que venham apoiar a assunção do saber discente.

\title{
Considerações Finais
}

A importância de análises acuradas sobre como tem se dado a verificação institucional do aprendizado de Língua Materna por meio da Avaliação de Aprendizagem em Processo da Secretaria da Educação do Estado de São Paulo, faz-se necessária uma vez que refletimos que se trata de um teste padronizado aplicado em um grande conjunto de alunos da rede pública brasileira, a qual mobiliza montantes de recursos financeiros e pedagógicos para ocorrer, na atualidade, quatro vezes ao ano. Trata-se de um indicador que surgiu timidamente, sem muitas pretensões, sua implementação começou por amostragem e, hoje, seu vulto paira em todas as instituições escolares, em cada série, que recebe o carimbo estatal. Como nos faz refletir em seu artigo, José Marcelino Rezende Pinto,

Bem, aqui já surge uma questão: a qualidade da educação pode ser avaliada tãosomente pelo desempenho em testes padronizados que hoje inundam o país (Prova Brasil, Exame Nacional do Ensino Médio - Enem -, Sistema de Avaliação da Educação Básica - Saeb - e seus congêneres estaduais e municipais) e o mundo (sendo 
o Programme for International Studente Assessment - Pisa - o mais conhecido)? (PINTO, 2013, p. 3)

Somente o estado de São Paulo possui dois destes "congêneres" citados, o Sistema de Avaliação de Rendimento Escolar do Estado de São Paulo (SARESP), com mais de vinte anos e, ainda percebendo uma necessidade de acompanhamento mais próximo e extensivo ao longo do ano letivo, a AAP, que conforme dissemos, é afiliada de todos estes outros exames de maior tradição. Conforme podemos atentar no tópico deste artigo "A AAP na prática: apresentação de um estudo de caso", nos parece que a resposta para o excerto de Pinto (2013), acima, é não, porque com o perfil apresentado, parece-nos que a AAP da rede paulista busca mais fazer com que o aluno caia em armadilhas do texto do que, de fato, mostre a potência de seu aprendizagem ao longo de, no mínimo, oito anos, se pensarmos a nível formal de escolaridade, mas se pensarmos como falantes de língua portuguesa, mais de uma década, conforme a idade deles.

Um primeiro olhar mais atento, voltado em específico para o caderno de LP, não apenas no tocante à função da AAP, como seu funcionamento aplicado, foi o que iniciamos em nível de Mestrado, graças a oportunidade dada pelo programa PROFLETRAS, o qual leva a nós, professores de língua materna, inseridos em contexto, a refletir no que é posto sobre o currículo, avaliações, regimentos e afins. Assim, podemos dizer com razoável convicção, de que a AAP carece de mais detalhamentos, reflexões e reformulações para que todo o orçamento e recursos humanos utilizados tenham, de fato, validade ao contemplar o ensino, a avaliação e a recuperação de conteúdos no tocante ao aprendizado e uso do nosso código linguístico, não com base em boas notas para um melhor ranqueamento, mas para que a missão de formar um sujeito para o exercício da autonomia através do domínio da linguagem de que já é usuário nato.

\section{Referências}

BRASIL. Parâmetros curriculares nacionais: língua portuguesa. 2 ed. Brasília: MEC/SEF, 1997.

DIONISIO, A. P.; VASCONCELOS, L. J. Multimodalidade, gênero textual e leitura. In: BUNZEN, C.; MENDONÇA, M. (Orgs.). Múltiplas linguagens para o Ensino Médio. São Paulo: Parábola, 2013. p. 19-42.

DIONISIO, A. P. Gêneros textuais e multimodalidade. In: KARWOSKI, A. M.; GAYDECZKA, B.; BRITO, K. S. (Orgs.) Gêneros textuais: reflexões e ensino. 4. ed. São Paulo: Parábola, 2011. p. 137-152. 
FIORIN, J. L. Interdiscurividade e intertextualidade. In: BRAIT, B. (Org.) Bakhtin: outros conceitos-chave. São Paulo: Contexto, 2010. p. 161-193.

LOPES-DAMASIO, L.R ; PRADO, M.S ; PAIS, A. G. ; FERREIRA, A. M. G. ; SANTOS, L. P. S. ; FRAGA, W. M. Gramática, variação e ensino: uma perspectiva de análise da condicionalidade. In: CARVALHO, Kelly Cristiane Henschel Pobbe de; FERREIRA, Eliane Aparecida Galvão Ribeiro. (Org.). Reflexões sobre o ensino de Língua Portuguesa: diálogos entre escola e universidade. 1 ed. São Paulo: Big Time Editora, 2018, v. 1, p. 173-190.

MARCUSCHI, L. A. Gêneros textuais: definição e funcionalidade. In: DIONISIO, A. P.; MACHADO, A. R.; BEZERRA, M. A. (Orgs.). Gêneros textuais e ensino. São Paulo: Parábola, 2010. p. 19-38.

PRADO, Michelle De Souza; GARCIA, Daniela Nogueira De Moraes. Análise da matriz de competência em uma aplicação real da Avaliação da Aprendizagem em Processo de Língua Portuguesa da Secretaria da Educação do Estado de São Paulo. Revista de Estudos Linguísticos, Campinas, v. 46, n. 670, p. 675, 2018. Disponível em: <https://doi.org/10.21165/el.v46i2.1689>. Acesso em: 03 mar. 2018.

SÃO PAUlO (Estado). Secretaria da Educação. Proposta Curricular do Estado de São Paulo: Língua Portuguesa. Maria Inês Fini (coordenação geral). São Paulo: SE, 2008.

. Secretaria da Educação. Coordenadoria de Gestão da Educação Básica. Avaliação da Aprendizagem em Processo. Comentários e recomendações pedagógicas. Subsídios para o Professor de Língua Portuguesa. $8^{\circ}$ ano $/ 1^{\circ}$ semestre. São Paulo: SE, 2015. 40 p.

SANTOS, C. F. O ensino da língua escrita na escola: dos tipos aos gêneros textuais. In: SANTOS, C. F.; MENDONÇA, M.; CAVALCANTE, M. C. B. (Orgs.) Diversidade textual: os gêneros na sala de aula. Belo Horizonte: Autêntica, 2007.

Recebido em 21 de maio de 2018. Aceito em 18 de janeiro de 2019. 